Case Report

\title{
Evolution of SILS Cholecystectomy in the Caribbean: The Direct Transfascial Puncture Technique Using Conventional Instruments without Working Ports
}

\author{
Shamir O. Cawich, Dexter Thomas, Dale Hassranah, and Vijay Naraynsingh \\ Department of Clinical Surgical Sciences, University of the West Indies, St. Augustine Campus, St. Augustine, Trinidad and Tobago \\ Correspondence should be addressed to Shamir O. Cawich; socawich@hotmail.com
}

Received 7 May 2014; Accepted 15 September 2014; Published 2 October 2014

Academic Editor: Boris Kirshtein

Copyright (C) 2014 Shamir O. Cawich et al. This is an open access article distributed under the Creative Commons Attribution License, which permits unrestricted use, distribution, and reproduction in any medium, provided the original work is properly cited.

\begin{abstract}
Introduction. Single incision laparoscopic cholecystectomy (SILC) has become accepted as an alternative to conventional multiport cholecystectomy. However, SILC is still limited in applicability in low resource centres due to the expense associated with specialized access platforms, curved instruments, and flexible scopes. Presentation of Case. We present three cases where a modified SILC technique was used with conventional instruments and no working ports. The evolution of this technique is described. Discussion. In order to contain cost, we used conventional instruments and three transfascial ports placed in an umbilical incision, but we noted significant instrument clashes that originated at the port platforms. Therefore, we modified our technique by omitting ports for the working instruments. The technique allowed us to exchange instruments as necessary, maximized ergonomics, and prevented collisions from the bulky port platforms. Finally, the puncture left by the instrument alone did not require fascial closure at the termination of the procedure. Conclusion. The direct transfascial puncture using conventional laparoscopic instruments without working ports is a feasible option that minimizes cost and increases ergonomics.
\end{abstract}

\section{Introduction}

Navarra et al. were the first to report the completion of a cholecystectomy through a single periumbilical incision in 1997 [1]. Initially, single incision laparoscopic cholecystectomy (SILC) was slow to gain traction because it was technically difficult and expensive due to need for specialized access platforms, curved instruments, and flexible tip laparoscopes. However, over the past decade SILC has become widely accepted as a feasible and safe alternative to multiport cholecystectomy. There have been increasing reports of modified SILC techniques using straight instruments [2-10] and modified access platforms [10-17].

The first SILC in the Caribbean was performed in 2009 [2]. Since this time, the technique has undergone several adaptations. We report the evolution in instrumentation and accesses in our practice of SILC in a limited-resource Caribbean setting.

\section{Presentation of a Case}

At our institution, three patients underwent SILC using a modified technique with conventional instruments. A $2 \mathrm{~cm}$ incision was created across the umbilicus. The skin was undermined in order to maximize fascial exposure. An $11 \mathrm{~mm}$ incision was created in the fascia at the left side of the fascial window. A purse string suture was inserted at the margins of the fascial incision using $1 / 0$ prolene sutures. A $10 \mathrm{~mm}$ optical port was placed in the incision. The purse string suture was tightened to create a seal and insufflation commenced to achieve a $12 \mathrm{mmHg}$ pneumoperitoneum. A $5 \mathrm{~mm}$ trocar introducer was then used to puncture the fascia at the right side of the wound (Figure 1). The introducer was withdrawn and a $5 \mathrm{~mm}$ instrument immediately advanced across the fascia through the tract. This was the most commonly utilized instrument for the surgeon and therefore would require the least "change." In our hands, this was an electrocautery hook. 


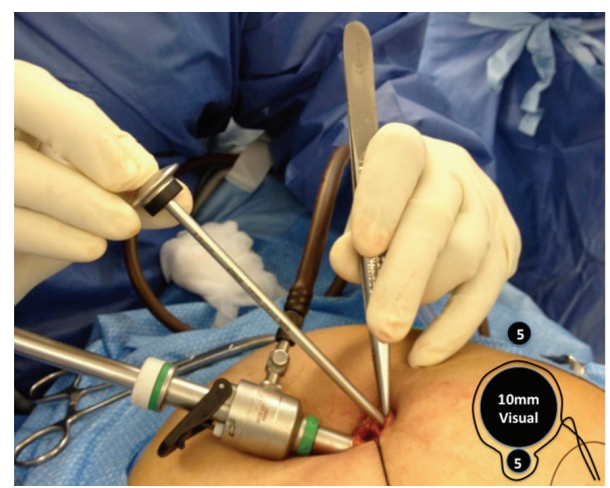

FIGURE 1: The $10 \mathrm{~mm}$ visual port is placed at the right side of the fascial window. A $5 \mathrm{~mm}$ working instrument will be passed alongside, encircled by a purse string suture (inset). A $5 \mathrm{~mm}$ introducer is used to puncture the fascia at the left side of the fascial window to allow a $5 \mathrm{~mm}$ instrument to be passed directly across the fascial tract outside the purse string suture (inset).

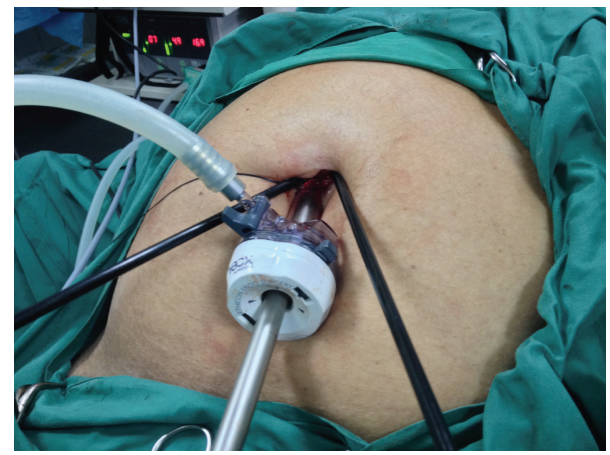

FIGURE 2: $10 \mathrm{~mm}$ visual port is placed in the umbilical incision and a $5 \mathrm{~mm}$ Maryland's grasper passes beside the visual port, both encircled by a purse string suture to create a seal. A $5 \mathrm{~mm}$ working instrument (cautery hook) is passed directly across the fascia outside the purse string suture.

To complete the cholecystectomy, the purse string suture was relaxed and a $5 \mathrm{~mm}$ straight instrument was passed beside the optical port (Figure 2). The purse string was tightened, encircling both instruments to regain a seal and reestablish a pneumoperitoneum. The cholecystectomy then proceeded in a normal fashion by dissecting Calot's triangle to achieve Strasberg's critical view (Figure 3). The cystic artery and duct were then clipped using a $5 \mathrm{~mm}$ clip applicator passed beside the visual port within the purse string suture. After division of these structures, the cautery hook was used to dissect the gallbladder from the hepatic bed.

Three procedures were completed with a mean operating time of 42 minutes. There were no conversions to open or multiport cholecystectomies. No complications were recorded.

\section{Discussion}

The first SILC in the Caribbean was performed in Jamaica in 2009 [2]. There are several challenges preventing minimally

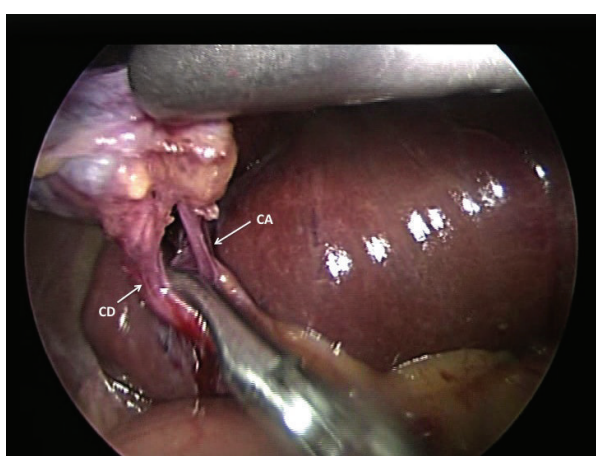

FIgURE 3: A $30^{\circ}$ laparoscope is used to demonstrate Strasberg's critical view during the SILC. Cystic duct (CD) and cystic artery (CA) are demonstrated.

invasive surgery from being established in this environment [18-20]. At the forefront is the fact that this is a developing nation with an underfunded health care system [18]. The public health care system cannot afford to procure access platforms, flexible scopes, or curved instruments. Therefore, our SILC technique was modified out of necessity to one using straight instruments and conventional laparoscopes [9]. Similarly, many authors report having reverted to the use of conventional instruments for SILC [2-10].

However, our technique continued to evolve since we had not found an acceptable and affordable access platform. Our first SILC was performed with donated SILS ports (Covidien Inc., Norwalk, CT, USA) but after the donated supplies depleted, we were forced to experiment with different types of accesses. To contain cost, we attempted using three reusable transfascial ports placed in an umbilical incision. The technique achieved the goal of cost-containment but it increased the technical difficulty of SILC because of instrument clashes.

We noticed that the "instrument clashes" did not involve the instruments but occurred between the port platforms. The natural progression was to omit the ports and pass the instruments directly across the fascia. Therefore, we modified the technique by omitting ports for our working instruments. By passing one instrument beside the optical port, we were able to exchange instruments during the procedure as necessary. Since this instrument was only $5 \mathrm{~mm}$ in diameter, a seal could be maintained by tightening the purse string suture that encircled the optical port and working instrument.

The second working instrument was passed directly across the fascia following the tract created by a puncture from a $5 \mathrm{~mm}$ optical trocar introducer. By omitting the working port, the bulky port platforms were not present so collisions could only originate from the instruments themselves-which were significantly smaller in diameter. This technique also allowed us to place this instrument at the right most extent of the wound, maximizing distance between the instruments. These two factors resulted in increased maneuverability of the working instruments. Although it did not fully compensate for the lack of triangulation inherent to SILC, the instruments were now in a position where we could perform intracorporeal tasks much more ergonomically. An added benefit was that the fascial defect left by the 
instrument alone did not require closure at the end of the procedure.

There have been many modifications of SILC accesses. Peritoneal access using multiple low profile ports which are in a single incision has been described $[5,6]$, but this does not completely overcome the problem of port platform collisions. Many authors have described the use of a surgical glove with conventional ports $[10-14,16,17]$ or modified syringes [15] tied into the fingers. However, all descriptions of the glove ports require the use of a wound retractor ring to maintain the seal that also incurs cost. Our modification overcomes both problems since it does not require the use of working ports or wound retractors and only creates collisions from the instruments themselves.

By reducing the amount of consumables required for each operation to a single $12 \mathrm{~mm}$ optical port (Covidien Inc., Norwalk, CT, USA) and standard $35 \mathrm{~cm}$ instruments, the direct transfascial puncture technique reduces the cost of this operation. We compared this to other methods that were available for SILC using current market prices from local distributors. The cost of one SILS port (Covidien Inc., Norwalk, CT, USA) on the local market was USD \$470.21. Using the glove method with one $12 \mathrm{~mm}$ port, two $5 \mathrm{~mm}$ ports, and a wound protector (Covidien Inc., Norwalk, CT, USA), the cost of the procedure amounted to USD \$209.01. Using the method with a $12 \mathrm{~mm}$ with two $5 \mathrm{~mm}$ ports placed in a single umbilical incision, the cost of the procedure was USD \$109.51. In comparison, using the direct transfascial puncture technique with only one $12 \mathrm{~mm}$ port (Covidien Inc., Norwalk, CT, USA), the cost of consumables for this procedure was only USD $\$ 37.85$. Compared to all the other methods, the cost associated with the direct transfacial puncture technique resulted in cost savings.

\section{Conclusion}

The direct transfascial puncture technique using conventional laparoscopic instruments without working ports is a feasible option. It minimizes cost and increases surgeon ergonomics for SILC. However, a series with larger case volumes is needed to definitively state the efficacy of this procedure.

\section{Consent}

Written informed consent was obtained from the patient for publication of this case report and case series and accompanying images. A copy of the written consent is available for review.

\section{Disclosure}

There are no additional acknowledgments and no source of funding was available for the preparation of this paper.

\section{Conflict of Interests}

The authors declare that there is no conflict of interests regarding the publication of this paper.

\section{References}

[1] G. Navarra, E. Pozza, S. Occhionorelli, P. Carcoforo, and I. Donini, "One-wound laparoscopic cholecystectomy," British Journal of Surgery, vol. 84, no. 5, p. 695, 1997.

[2] S. O. Cawich, M. Albert, S. K. Mohanty, and G. Dapri, "Laparoscopic cholecystectomy with straight instruments through one incision: learning from the early experience in Jamaica," International Journal of Surgery, vol. 28, no. 4, 2012.

[3] N. Garcia-Henriquez, S. R. Shah, and T. D. Kane, "Singleincision laparoscopic cholecystectomy in children using standard straight instruments: a surgeon's early experience," Journal of Laparoendoscopic and Advanced Surgical Techniques, vol. 21, no. 6, pp. 555-559, 2011.

[4] S.-H. Chuang, P.-H. Chen, C.-M. Chang, and C.-S. Lin, "Singleincision vs three-incision laparoscopic cholecystectomy for complicated and uncomplicated acute cholecystitis," World Journal of Gastroenterology, vol. 19, no. 43, pp. 7743-7750, 2013.

[5] H. Cui, J. J. Kelly, and D. E. M. Litwin, "Single-incision laparoscopic cholecystectomy using a modified dome-down approach with conventional laparoscopic instruments," Surgical Endoscopy and Other Interventional Techniques, vol. 26, no. 4, pp. 1153-1159, 2012.

[6] H. Cui, "Single incision laparoscopic cholecystectomy using the one-incision three-trocar technique with all straight instruments: how I do it?" Frontiers of Medicine in China, vol. 5, no. 3, pp. 283-287, 2011.

[7] S. O. Cawich, M. Albert, and S. K. Mohanty, "Laparoscopic cholecystectomy using standard instruments through a single umbilical incision: feasibility in Jamaica," The West Indian Medical Journal, vol. 62, no. 1, pp. 1-2, 2013.

[8] M. T. Oruc and M. U. Ugurlu, "Extra-umbilical singleincision laparoscopic cholecystectomy with standard laparoscopic instruments," Scandinavian Journal of Surgery, vol. 102, no. 3, pp. 209-214, 2013.

[9] S. O. Cawich, S. K. Mohanty, M. Albert, L. K. Simpson, K. O. Bonadie, and G. Dapri, "Single port laparoscopic cholecystectomy with straight instruments: a national audit in Jamaica," Caribbean Medical Journal, vol. 74, no. 2, pp. 5-7, 2012.

[10] T. H. Hong, Y. K. You, and K. H. Lee, "Transumbilical singleport laparoscopic cholecystectomy: scarless cholecystectomy," Surgical Endoscopy, vol. 23, no. 6, pp. 1393-1397, 2009.

[11] E. Khiangte, I. Newme, P. Phukan, and S. Medhi, "Improvised transumbilical glove port: a cost effective method for single port laparoscopic surgery," Indian Journal of Surgery, vol. 73, no. 2, pp. 142-145, 2011.

[12] E. Khiangte, I. Newme, K. Patowary, and P. Phukan, "Singleport laparoscopic cholecystectomy in situs inversus totalis using the E.K. glove port," Journal of Minimal Access Surgery, vol. 9, no. 4, pp. 180-182, 2013.

[13] E. Orozakunov, C. Akyol, S. I. Kayilioglu, U. Tantoglu, S. I. Basceken, and A. Cakmak, "Single-Port laparoscopic surgery by use of a surgical glove port: initial experience with 25 cases," Chirurgia, vol. 108, no. 5, pp. 670-672, 2013.

[14] L. Livraghi, M. Berselli, V. Bianchi, L. Latham, L. Farassino, and E. Cocozza, "Glove technique in single-port access laparoscopic surgery: results of an initial experience," Minimally Invasive Surgery, vol. 2012, Article ID 415430, 4 pages, 2012.

[15] M. Tsujie, M. Ikenaga, A. Miyamoto et al., "Effectiveness of a surgical glove port with homemade trocars made of syringes for single incision laparoscopic cholecystectomy," HepatoGastroenterology, vol. 59, no. 120, pp. 2407-2409, 2012. 
[16] A. Barband, M. B. A. Fakhree, F. Kakaei, and A. Daryani, "Single-incision laparoscopic cholecystectomy using glove port in comparison with standard laparoscopic cholecystectomy SILC using glove port," Surgical Laparoscopy, Endoscopy and Percutaneous Techniques, vol. 22, no. 1, pp. 17-20, 2012.

[17] M. Hayashi, M. Asakuma, K. Komeda, Y. Miyamoto, F. Hirokawa, and N. Tanigawa, "Effectiveness of a surgical glove port for single port surgery," World Journal of Surgery, vol. 34, no. 10, pp. 2487-2489, 2010.

[18] S. O. Cawich, H. E. Harding, I. W. Crandon et al., "Leadership in surgery for public sector hospitals in Jamaica: strategies in the operating room," The Permanente Journal, vol. 17, no. 3, pp. 121-125, 2013.

[19] S. Cawich, S. Mohanty, K. Bonadie et al., "Laparoscopic inguinal hernia repair in a developing nation: short-term outcomes in 103 consecutive procedures," Journal of Surgical Technique and Case Report, vol. 5, no. 1, pp. 13-17, 2013.

[20] D. Dan, V. Naraynsingh, S. O. Cawich, and R. Jonnalagadda, "The history of laparoscopic general surgery in the Caribbean," West Indian Medical Journal, vol. 61, no. 4, pp. 465-469, 2012. 


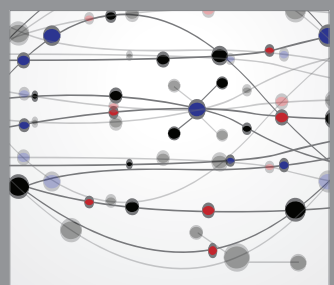

The Scientific World Journal
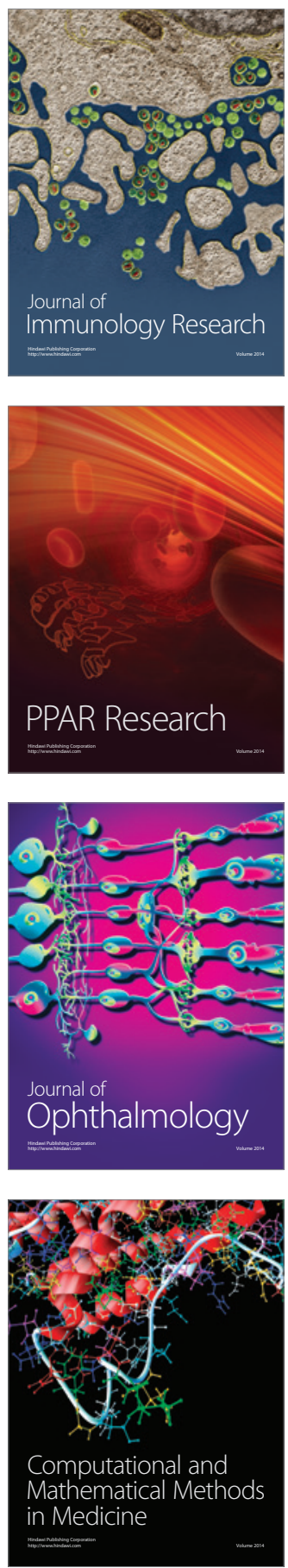

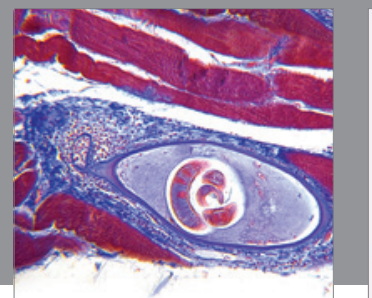

Gastroenterology

Research and Practice
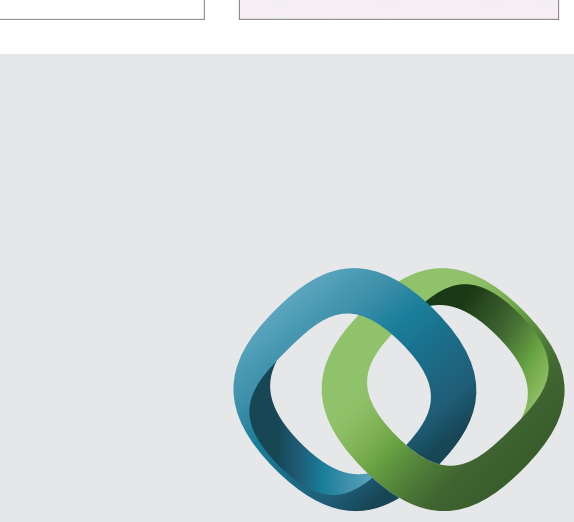

\section{Hindawi}

Submit your manuscripts at

http://www.hindawi.com
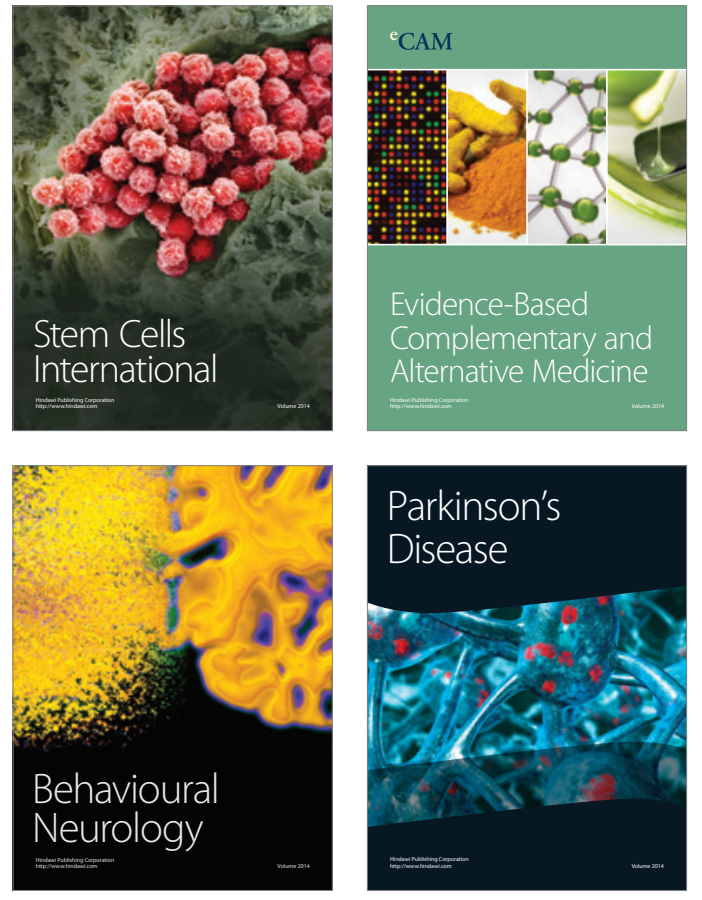
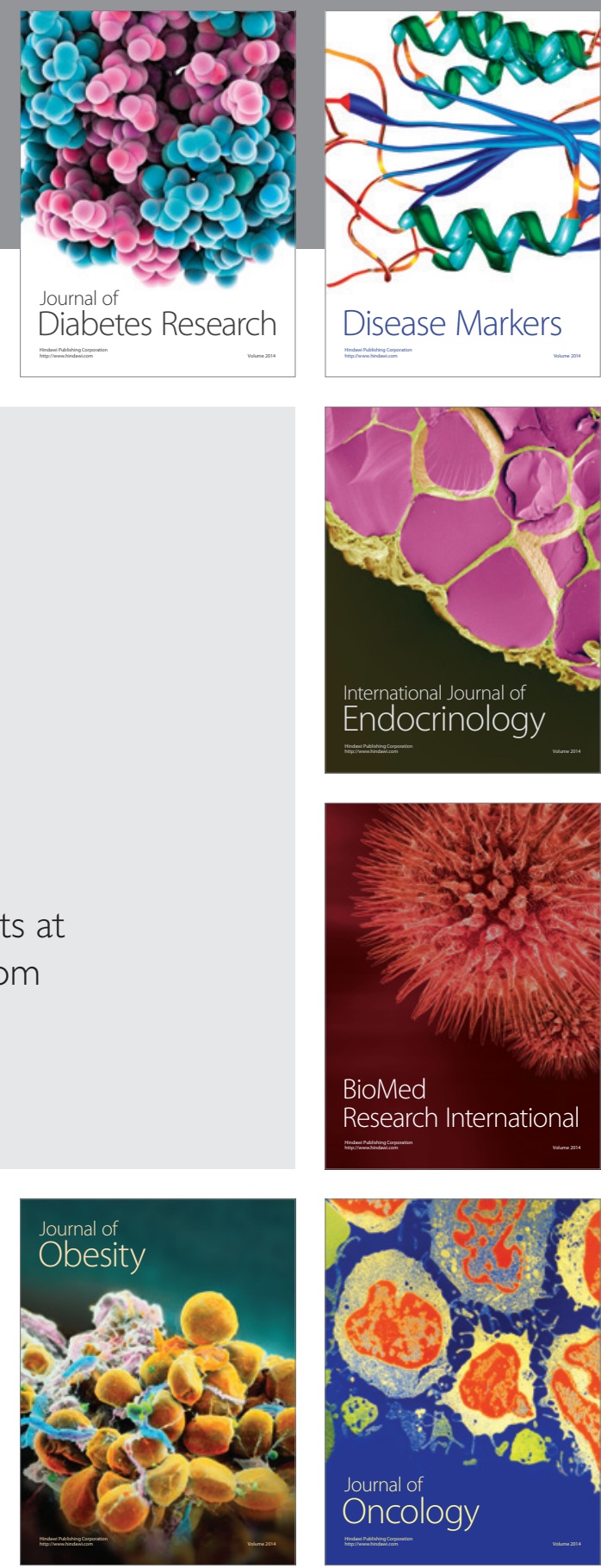

Disease Markers
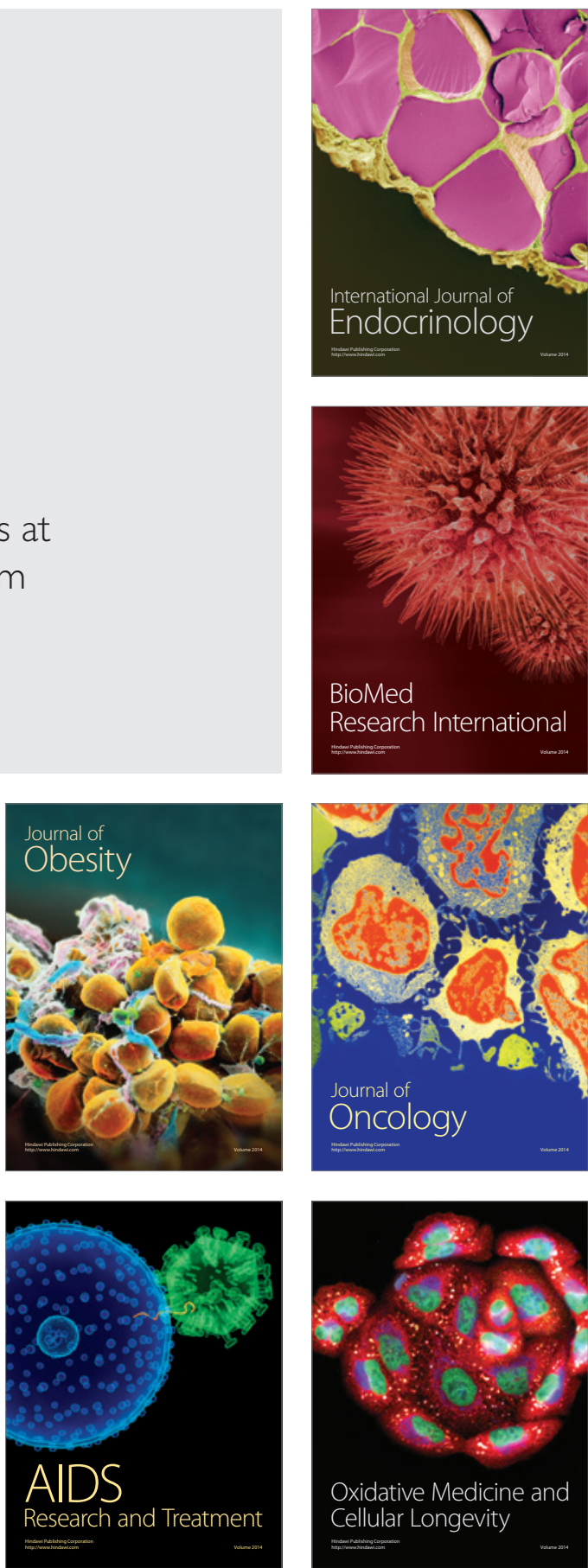